\title{
Axin-mediated CKI phosphorylation of $\beta$-catenin at Ser 45: a molecular switch for the Wnt pathway
}

\author{
Sharon Amit, ${ }^{1}$ Ada Hatzubai, ${ }^{1}$ Yaara Birman, ${ }^{1}$ Jens S. Andersen, ${ }^{2}$ Etti Ben-Shushan, ${ }^{1}$ \\ Matthias Mann, ${ }^{2}$ Yinon Ben-Neriah, ${ }^{1,3}$ and Irit Alkalay ${ }^{1}$ \\ ${ }^{1}$ The Lautenberg Center for Immunology, The Hebrew University-Hadassah Medical School, Jerusalem 91120, Israel; \\ ${ }^{2}$ Protein Interaction Laboratory, University of Southern Denmark, DK-5230 Odense M, Denmark
}

The Wnt pathway controls numerous developmental processes via the $\beta$-catenin-TCF/LEF transcription complex. Deregulation of the pathway results in the aberrant accumulation of $\beta$-catenin in the nucleus, often leading to cancer. Normally, cytoplasmic $\beta$-catenin associates with APC and axin and is continuously phosphorylated by GSK-3 $\beta$, marking it for proteasomal degradation. Wnt signaling is considered to prevent GSK-3 $\beta$ from phosphorylating $\beta$-catenin, thus causing its stabilization. However, the Wnt mechanism of action has not been resolved. Here we study the regulation of $\beta$-catenin phosphorylation and degradation by the Wnt pathway. Using mass spectrometry and phosphopeptide-specific antibodies, we show that a complex of axin and casein kinase I (CKI) induces $\beta$-catenin phosphorylation at a single site: serine 45 (S45).

Immunopurified axin and recombinant CKI phosphorylate $\beta$-catenin in vitro at S45; CKI inhibition suppresses this phosphorylation in vivo. CKI phosphorylation creates a priming site for GSK-3 $\beta$ and is both necessary and sufficient to initiate the $\beta$-catenin phosphorylation-degradation cascade. Wnt3A signaling and Dvl overexpression suppress $\mathbf{S 4 5}$ phosphorylation, thereby precluding the initiation of the cascade. Thus, a single, CKI-dependent phosphorylation event serves as a molecular switch for the Wnt pathway.

[Key Words: $\beta$-Catenin; axin; CKI; Ser 45 phosphorylation; Wnt regulation]

Received March 11, 2002; revised version accepted March 28, 2002.

Genetic studies in flies, frogs, and mammals positioned the Wnt pathway as a master regulator in animal development, both during embryogenesis and in the mature organism (Wodarz and Nusse 1998; Eastman and Grosschedl 1999; Peifer and Polakis 2000; Huelsken and Birchmeier 2001). A major target of the Wnt pathway is cytoplasmic $\beta$-catenin, which, when stabilized in response to Wnt signaling, enters the nucleus and serves as a coactivator of TCF/LEF-induced transcription (Willert and Nusse 1998; Bienz and Clevers 2000; Polakis 2000). Unstimulated cells harbor a cytoplasmic multiprotein complex containing $\beta$-catenin, the Ser/Thr kinase glycogen synthase kinase-3 $\beta$ (GSK-3 $\beta$ ), axin (Zeng et al. 1997; Ikeda et al. 1998; Sakanaka et al. 1998), or its homolog Axil/Conductin (Behrens et al. 1998; Yamamoto et al. 1998), and the adenomatous polyposis coli (APC) tumor suppressor (Groden et al. 1991; Kinzler et al. 1991). APC and axin are thought to play a scaffold function, facilitating the GSK-3 $\beta$ phosphorylation of $\beta$-catenin at the N-terminal region (Hart et al. 1998; Hinoi et al. 2000). This phosphorylation event(s) marks $\beta$-catenin for ubiquitination by the $\mathrm{SCF}^{\beta-\operatorname{TrCP}} \mathrm{E} 3$ and subsequent protea-

${ }^{3}$ Corresponding author.

E-MAIL yinon@cc.huji.ac.il; FAX 972-2-6758935.

Article and publication are at http://www.genesdev.org/cgi/doi/10.1101/ gad.230302. somal degradation (Aberle et al. 1997; Hart et al. 1999; Kitagawa et al. 1999; Latres et al. 1999; Winston et al. 1999). Wnt signaling is initiated by secreted Wnt proteins, which bind to members of the frizzled receptor family (Wodarz and Nusse 1998). Wnt-binding results in the activation of dishevelled (Dvl-1, Dvl-2, and Dvl-3 in humans and mice; Boutros and Mlodzik 1999), which, via its association with axin, prevents GSK-3 $\beta$ from phosphorylating $\beta$-catenin, leading to its stabilization (Yamamoto et al. 1999). The mechanism of Dvl action in inhibiting $\beta$-catenin phosphorylation by GSK-3 $\beta$ is mostly unknown. According to a prevailing model, it involves FRAT (GBP), a GSK-3 $\beta$-binding protein that displaces axin from GSK-3 $\beta$, resulting in failure to phosphorylate $\beta$-catenin (Li et al. 1999; Farr et al. 2000; Bax et al. 2001; Fraser et al. 2001). However, there is currently no evidence linking Dvl activity directly to FRAT-induced axin-GSK-3 $\beta$ dissociation.

The importance of $\beta$-catenin phosphorylation in controlling its degradation has been mainly inferred from studies of $\mathrm{N}$-terminal $\beta$-catenin mutations in tumor cells (Polakis 2000). These, like aberrations of APC or axin, lead to excessive accumulation of $\beta$-catenin in the nucleus and deregulated expression of its target genes, promoting neoplastic transformation (Morin et al. 1997; Rubinfeld et al. 1997; Sparks et al. 1998). $\beta$-Catenin mutations cluster around the $\mathrm{SCF}^{\beta-\mathrm{TrCP}}$-binding site and 
are, therefore, thought to compromise $\beta$-catenin ubiquitination and its consequent degradation (Wong et al. 2001). Many of these stabilizing mutations occur at Ser/ Thr residues along a putative GSK-3 $\beta$ phosphorylation cascade that molds the E3 binding motif, emphasizing the role of GSK-3 $\beta$ in determining $\beta$-catenin stability (Polakis 2000). Yet, serine 45 (S45), the single most frequent tumor mutation spot, does not conform to a GSK$3 \beta$ site (Polakis 2000; Wong et al. 2001). This may have contributed to the notion that $\beta$-catenin is an unusual GSK-3 $\beta$ substrate that obviates the need for primingphosphorylation as a trigger for initiating a GSK-3 $\beta$ phosphorylation cascade (Ding et al. 2000; Cohen and Frame 2001; Harwood 2001). Contrary to this view, our study shows that $\beta$-catenin phosphorylation at $S 45$ is induced by an axin-CKI complex independently of GSK-3 $\beta$. Furthermore, this molecular event appears to constitute a major target for Wnt pathway regulation.

\section{Results}

Axin induces the $\beta$-catenin phosphorylationdegradation cascade, initiated by the phosphorylation at serine residue 45

To study the phosphorylation cascade that promotes $\beta$-catenin degradation, we have constructed a simple protein expression system in 293 cells: the combined overexpression of axin and GSK-3 $\beta$ triggers the degradation of exogenously expressed $\beta$-catenin (Myc-tagged; Fig. 1a). In this system, neither component alone was sufficient to promote $\beta$-catenin degradation over a wide range of plasmid expression (Fig. 1a; data not shown). Degradation was blocked upon cell treatment with the proteasome inhibitor MG-132 (Fig. 1b) or by overexpression of a dominant-negative $\beta$-TrCP (Fig. 1a, lane 7), a recognized $\beta$-catenin ubiquitin ligase (Polakis 2000). Cell lysates were analyzed for $\beta$-catenin phosphorylation using a series of commercial anti- $\beta$-catenin phosphopeptide antibodies: antibody specific for both pT41 and pS45 $(\alpha \mathrm{p} 41,45)$, and antibodies recognizing either pS33 or pS37. No phosphorylation was detected upon transfection of Myc- $\beta$-catenin alone, or in combination with GSK-3 $\beta$ (Fig. 1b, lanes 2,3). Axin expression induced a prominent signal with $\alpha \mathrm{p} 41,45$ and minor signals with ap33 and $\alpha$ p37, possibly attributable to endogenous GSK- $3 \beta$ activity (Fig. 1b, lane 5). Coexpression of axin and GSK-3 $\beta$ enhanced S33 and S37 phosphorylation to a great extent (10- to 30 -fold), whereas the T41/S45 phosphorylation signal was modestly enhanced (two- to fourfold, Fig. 1b, cf. lanes 4 and 5), probably caused by GSK$3 \beta$-mediated T41 phosphorylation. In contrast, an N-terminal mutated $\beta$-catenin (dominant-positive, DP) did not show any phosphorylation signal and was stable, irrespective of proteasomal inhibition (Fig. 1a,b). S45 phosphorylation was also observed upon overexpression of APC, yet to a much lower extent (data not shown). This may suggest that APC has a role in the priming reaction, which is likely limited to supporting the activity of axin. Indeed, mutational analysis of APC in cancer has shown that many APC mutations prohibit its engagement with axin but preserve $\beta$-catenin association (Hart et al. 1998; Fearnhead et al. 2001).

To resolve the phosphorylation specificity of axin and GSK-3 $\beta, \beta$-catenin phosphorylation was further analyzed by mass spectrometry (MS). MS analysis showed trace phosphorylation of the $\mathrm{N}$-terminal region of $\beta$-catenin when transfected alone (Fig. 1c, panels 1,2). Axin coexpression resulted in a major phosphorylation signal at S45, with barely detectable phosphorylation signals at any other potential $\mathrm{N}$-terminal phosphorylation site (Fig. 1c, panels 3,4,7). Conversely, the combined expression of axin and GSK-3 $\beta$ resulted in phosphorylation signals at S45 and four consecutive N-terminal phosphorylation sites: T41, S37, S33 (Fig. 1c, panels 6,8), and S29 (data not shown), with decreasing signal intensity.

$\beta$-Catenin studies in a variety of human tumors indicated that several potential $\mathrm{N}$-terminal phosphorylation sites are often mutated, leading to stabilization and enhanced nuclear expression of the mutated protein (Morin et al. 1997; Rubinfeld et al. 1997; Wong et al. 2001). Many of these tumor mutations are concentrated around the consensus binding site of $\beta$-TrCP $\left(\mathrm{DS}^{\star} \mathrm{GXXS}^{\star}, \mathrm{S}^{\star}\right.$ denotes phosphoserine; Yaron et al. 1998), accounting for $\beta$-catenin stabilization. However, two common mutation sites, S45 and T41, are positioned C-terminally to the canonical $\beta$-TrCP recognition motif. Thus, stabilization of $\beta$-catenin by T41/S45 mutations calls for a different explanation. One possibility is the formation of a redundant E3 anchoring site around pT41 and pS45 $\left(S^{\star} X_{\left.X X S^{\star}\right)}\right.$ that is absent in the mutants. The other possibility is that these mutations influence the phosphorylation of S33 and S37, which is necessary for generating the $\beta$-TrCP binding site. To address this issue, we created a series of point mutations at the MS-detected Nterminal phosphorylation sites and examined their phosphorylation and degradation in the 293 system. Expression of axin or axin-GSK-3 $\beta$ yielded phosphorylation signals with $\alpha \mathrm{p} 41,45$ in all the mutants, aside from S45F (Fig. 2a). This pertains also to the T41A mutant, which can only be phosphorylated on S45, indicating that axin may induce an exclusive S45 phosphorylation. On the other hand, none of the mutants, with the exception of S29F, was phosphorylated both at S33 and S37 in response to axin-GSK-3 $\beta$ transfection (Fig. 2a). Conjointly with their phosphorylation status, only wild-type and S29F $\beta$-catenin were degraded following coexpression of axin-GSK-3 $\beta$ (Fig. 2b). All the other mutants resisted degradation, in accordance with the stability of their tumor counterparts in human cancer (Polakis 2000). As mutations at S37 and S33 allow T41/S45 phosphorylation (Fig. 2a, lanes 7-12), but resist degradation (Fig. 2b, lanes 5-8), the occurrence of a functionally redundant $\beta$-TrCP recognition site downstream of S37 is unlikely. Therefore, it appears that phosphorylation at S45 initiates a linear GSK-3 $\beta$ cascade, in which each phosphorylation site serves as a necessary priming site for the successive one. Although it runs all the way through S29, the aim of the cascade is apparently restricted to generating the canonical $\beta$-TrCP recognition 
Amit et al.

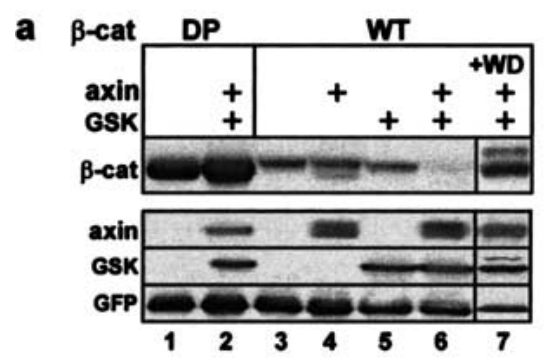

b

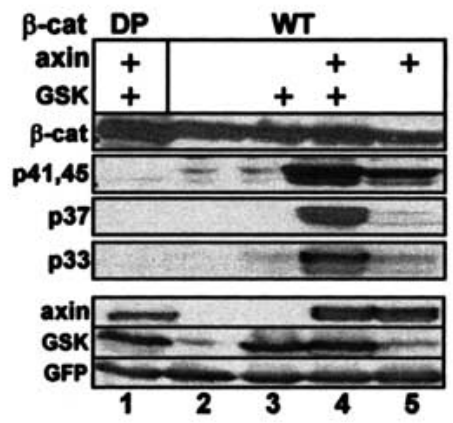

c
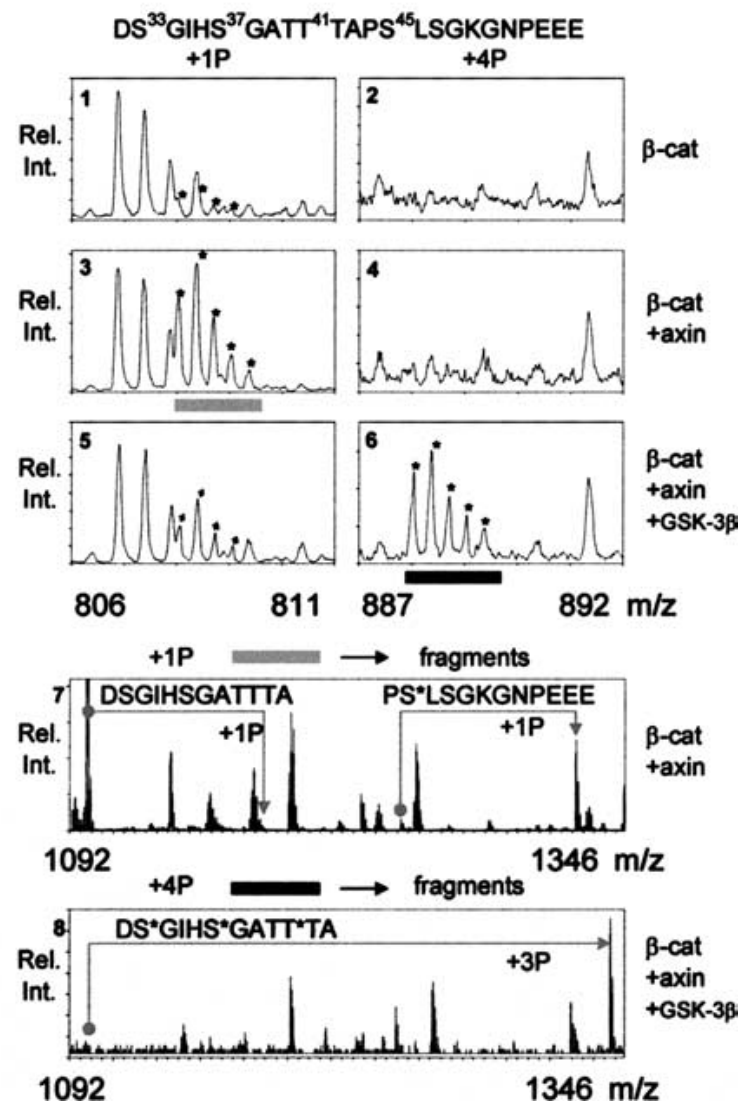

Figure 1. Axin induces $\beta$-catenin phosphorylation exclusively on S45, yet proteasomal degradation requires further GSK-mediated phosphorylation at T41, S37, and S33. (a) $\beta$-Catenin (wild-type or N-terminal-mutated $\beta$-catenin; DP) stability in response to transfection of axin and GSK-3 $\beta$. A dominant-negative Flag- $\Delta$ F-box- $\beta$-TrCP fragment (WD) was included in lane 7 . A GFP expression vector was included in all transfections as an expression reference. (b) $\beta$-Catenin phosphorylation analysis with anti-phosphopeptide antibodies in proteasome-inhibited cells. (c) $\beta$-Catenin phosphorylation analysis by mass spectrometry (MS). Immunopurified Flag- $\beta$ catenin bands were digested with Asp-N endoproteinase, and the resulting N-terminal peptides, including Asp17-Leu31 and Asp32Glu55 (shown on top) were analyzed by nanoelectrospray MS. The $\mathrm{m} / \mathrm{z}$ ratios shown (six top panels) correspond to triple-charged $[\mathrm{M}+3 \mathrm{H}]^{3+}$ ions of the Asp32-Glu55 peptide, marked by asterisks (including all its isotopic variants). Displayed are spectra of peptides containing $1(+1 \mathrm{P})$ and $4(+4 \mathrm{P})$ phosphate groups from $\beta$-catenin alone (panels 1,2$), \beta$-catenin coexpressed with axin (panels 3,4), and axin plus GSK-3 $\beta$ (panels 5,6). $[\mathrm{M}+3 \mathrm{H}]^{3+}$ ions from bar-marked peptides (gray and black) were selected for fragmentation. The spectra in the lower panels $(7,8)$ correspond to fragments derived from MS/MS of the gray bar peptide (from panel 3) and black bar peptide (from panel 6). The Asp32-Glu55 peptide was fragmented by MS/MS into halves, a C-terminal half containing Ser 45 and an N-terminal half containing Ser 33/Ser 37/Thr 41. Whereas the gray bar C-terminal fragment is mostly phosphorylated, the N-terminal fragment is mostly unphosphorylated (panel 7). The relationship of nonphosphorylated to phosphorylated (+1P) fragments is indicated by angled arrows. The black bar N-terminal fragment (panel 8 ) is mostly triply phosphorylated $(+3 \mathrm{P})$. Its C-terminal fragment is singly phosphorylated (data not shown), similarly to that of the gray bar. MS/MS analysis of the Asp17-Leu 31 peptide (from $+1 \mathrm{P}$ of the MS) reveals minor, yet significant Ser 29 phosphorylation (data not shown).

site around $\mathrm{S} 33 / 37$. This presumption is supported by the prevalence of tumor mutations at Asp 32 and Gly 34 (Wong et al. 2001), which do not affect the phosphorylation, but are likely to compromise the $\beta$-TrCP recognition motif.

S45 phosphorylation, which by itself is GSK-3ß-independent, is both necessary and sufficient to initiate a GSK-3ß-dependent phosphorylation-degradation cascade

The above experiments implicate axin in S45 phosphorylation, but do not rule out a contribution of GSK-3 $\beta$ to this event. GSK-3 $\beta$ is traditionally known to target the phosphorylation of +4P-primed substrates (Frame et al. 2001), a specificity supported by recent structural studies of the enzyme (Dajani et al. 2001). The fact that the S45 phosphorylation site is not preceded by a $+4 \mathrm{P}$ priming site led to the proposition that the molecular complex of axin and GSK- $3 \beta$ is capable of bypassing the priming requirement of the uncomplexed enzyme (Cohen and Frame 2001). To assess the contribution of GSK-3 $\beta$ in axin-mediated S45 phosphorylation, two types of experiments were carried out. In the first set, 293 cells were incubated prior to harvesting with $\mathrm{LiCl}$, a GSK-3 $\beta$ inhibitor capable of mimicking a Wnt effect (Klein and 

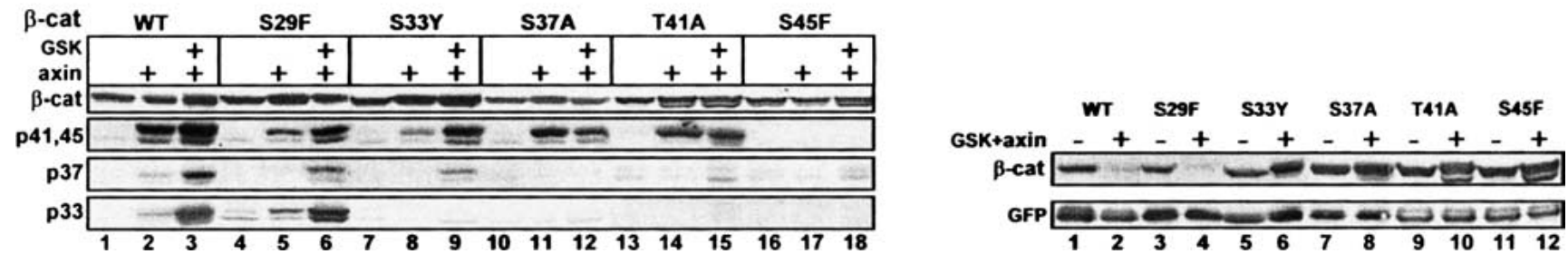

Figure 2. Mutations at four $\beta$-catenin $\mathrm{N}$-terminal phosphorylation sites curtail the phosphorylation cascade, leading to $\beta$-catenin stabilization. (a) Wild-type and mutated $\beta$-catenin from MG-132 treated cells were detected with anti-Myc or anti-phospho- $\beta$-catenin antibodies. (b) Stability analysis of phosphorylation-site $\beta$-catenin mutants in MG-132-untreated cells.

Melton 1996; Stambolic et al. 1996). Whereas the modest axin-induced S33/37 phosphorylation of wild-type $\beta$-catenin was abolished by $\mathrm{LiCl}$, the counterpart $\mathrm{T} 41 /$ S45 phosphorylation signal was minimally affected (Fig. 3a (top), cf. lanes 3 and 6). Similarly, no difference was observed in the MS analysis of S45 peptides from LiCltreated versus untreated cells (data not shown). Moreover, LiCl treatment had no effect on S45 phosphorylation of a T41A mutated $\beta$-catenin (Fig. 3a (bottom), cf. lanes 3 and 6), indicating that S45 phosphorylation was independent of GSK-3 $\beta$.

In the second set of experiments, we tested a mutated axin (Leu 525 converted to Pro; L525P-axin), which is incapable of interacting with GSK-3 $\beta$ (Fig. $3 b$; Smalley et al. 1999; Rubinfeld et al. 2001). L525P-axin was as effective as wild-type axin in inducing S45 phosphorylation (Fig. 3c, lanes 2,4 and MS analysis, see Fig. 6c, below). Unlike wild-type axin, the L525P mutant is unable to engage the endogenous GSK-3 $\beta$ for phosphorylating S33/ 37 (Fig. 3c, cf. lanes 2 and 4). However, when complimented by exogenous GSK-3 $\beta$, L525P-axin and wild-type axin generated comparable $\mathrm{S} 33 / 37$ phosphorylation signals (Fig. 3c, lanes 3,5; MS data not shown) and $\beta$-catenin degradation (Figs. 1a, lane 6, and 3c, lane 7). Cumulative$1 y$, these experiments show that the priming phosphorylation at S45 does not require GSK-3 $\beta$, but a different protein kinase.

Our data show that S45 phosphorylation is essential for initiating GSK-3 $\beta$ phosphorylation, yet do not indicate whether it is sufficient to mobilize the cascade. To address this question, we constructed a $\beta$-catenin containing a surrogate protein kinase A (PKA)-mediated phosphorylation site at S45 (45PKA). This manipulation did not affect the expression or stability of $\beta$-catenin (data not shown), but resulted in its constitutive S45 phosphorylation in 293 cells (Fig. 4, lane 1), which was inhibited by H89, a specific PKA inhibitor (data not shown). S45 phosphorylation of 45PKA did not require axin, nor was it enhanced by axin overexpression (Fig. 4, lanes 1,2). Therefore, 45PKA proved instrumental in studying the initiation and progression of the GSK- $3 \beta$ phosphorylation cascade independently of axin. GSK- $3 \beta$ transfection resulted in pronounced S33/37 phosphorylation of the 45PKA mutant (Fig. 4, lane 3), as well as its complete degradation (Fig. 4, lane 5). This is in striking contrast to the inability of GSK- $3 \beta$ to induce phosphory- lation and degradation of wild-type $\beta$-catenin when transfected alone (Fig. 1). To control the effect of wildtype GSK-3 $\beta$, we used an R96A-GSK-3 $\beta$ mutant, which cannot accommodate a priming phosphoserine and is, therefore, unable to phosphorylate priming-dependent substrates (Frame et al. 2001). R96A-GSK-3 $\beta$ did not induce 45PKA phosphorylation at S33/37 (Fig. 4, lane 4) and its subsequent degradation (Fig. 4, lane 6). These results indicate that $\beta$-catenin is a bona fide primingdependent substrate for GSK- $3 \beta$ and that S45 priming is both necessary and sufficient for driving the GSK- $3 \beta$ cascade. Nevertheless, the above experiments cannot address additional roles for axin in the cascade. It is possible that when GSK-3 $\beta$ is present in limiting amounts, axin helps to recruit GSK-3 $\beta$ to $\beta$-catenin. In support of such a role are the data comparing the effect of wild-type axin with that of L525P-axin: the latter, which is incapable of associating with endogenous GSK- $3 \beta$, failed to induce S33/37 phosphorylation (Fig. 3c, lane 4).

\section{Axin-induced S45 phosphorylation is mediated by CKI}

To identify the axin-associated priming kinase, we immunopurified Flag-axin from transfected 293 cells and analyzed its endogenous associated proteins by LC/MS (see Materials and Methods). Only five protein kinases were detected in association with axin at a high score: The two GSK- 3 isoforms, $\alpha$ and $\beta$, and three CKI isoforms, $\varepsilon, \delta$, and $\alpha$. These CKI isoforms have a highly conserved kinase domain and appear to have similar or identical substrate specificity (Fish et al. 1995). Several studies implicated CKI $\varepsilon$ in the Wnt pathway, mostly as a positive effector (Peters et al. 1999; Lee et al. 2001; McKay et al. 2001; Gao et al. 2002). However, CKI $\varepsilon$ has been recently shown to interact with axin (Sakanaka et al. 1999; Rubinfeld et al. 2001), and it was proposed that this kinase mediates axin-induced APC phosphorylation, thereby stabilizing the $\beta$-catenin degradation complex (Rubinfeld et al. 2001). We have, therefore, evaluated CKI as a candidate S45-kinase in several assays, both in vitro and in vivo.

First, we tested the in vitro phosphorylation of $\beta$-catenin using an immunopurified Flag-axin (the LC/ MS preparation) and the recombinant enzymes, CKI (an N-terminal 318-aa fragment) and GSK-3 $\beta$ (Fig. 5 a). Both CKI $\delta$ and axin induced the phosphorylation of $\beta$-catenin 
Amit et al.
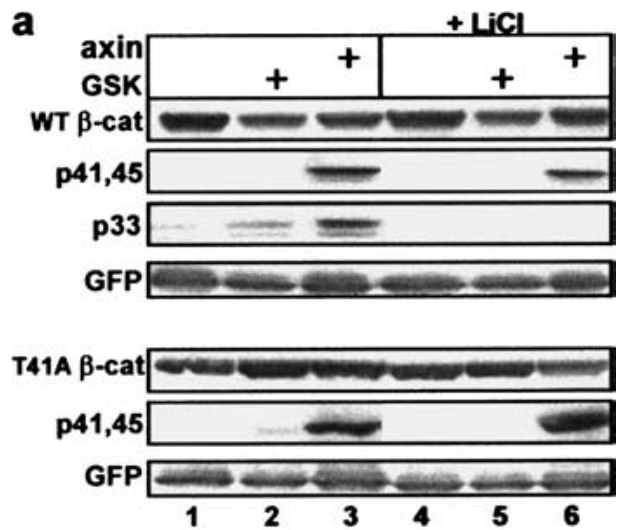

b
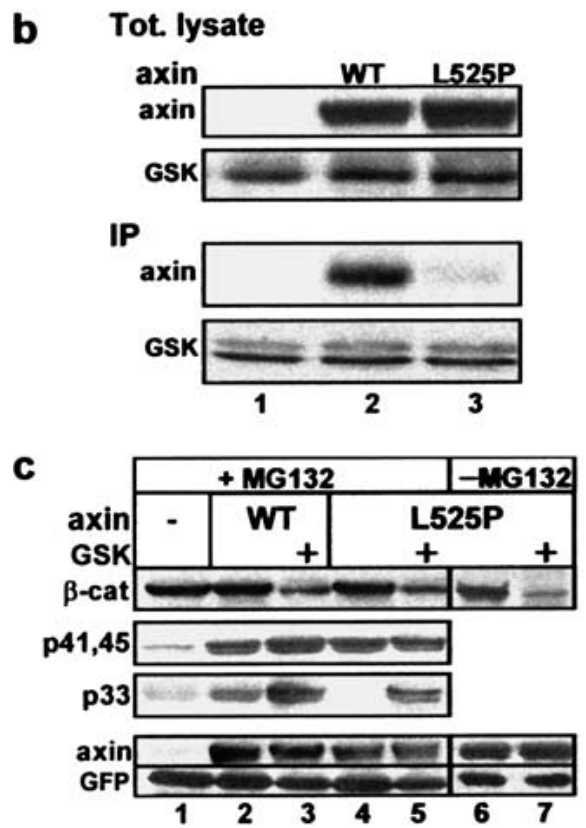

Figure 3. Axin-mediated S45 phosphorylation is GSK-3 $\beta$-independent. (a) S45 phosphorylation is not affected by LiCl. Analysis of wild-type or T41A $\beta$-catenin from MG-132-treated cells, with or without LiCl. No phosphorylation signal at S33/37 was detected in the T41A mutant (see Fig. 2a). (b) L525P-Axin does not bind GSK-3 $\beta$. Anti-Flag immunoprecipitation from cells transfected with Flag-GSK-3 $\beta$ and wild-type or L525P Myc-axin. (c) L525P-Axin induces S45 phosphorylation and supports a phosphorylation-degradation cascade in the presence of exogenous GSK- $3 \beta$. All cells were transfected with Myc- $\beta$-catenin and the indicated expression vectors.

at S45/T41, but not at S33 (Fig. 5a, lanes 3,7). To directly implicate CKI in priming the GSK-3 $\beta$-phosphorylation cascade, $\beta$-catenin was subjected to sequential phosphorylation by CKI followed by GSK- $3 \beta$. GSK- $3 \beta$ poorly phosphorylated $\beta$-catenin on its own (Fig. 5 a, lane 4 ), yet induced a pronounced pS33 signal following S45 phosphorylation by CKI (Fig. 5a, lane 5).

In another set of experiments, we analyzed the in vivo role of CKI in S45 phosphorylation using two dominantnegative CKI $\varepsilon$ constructs (dnXCKI $\varepsilon$ K85R and D128N; McKay et al. 2001) and a specific CKI inhibitor (CKI-7;
Chijiwa et al. 1989). Coexpression of either $\operatorname{dnXCKI} \varepsilon$, but not the wild-type kinase, with axin, suppressed the ability of axin to induce S45 phosphorylation in 293 cells (Fig. 5b, lanes 3-5). Next, we tested the effect of CKI-7 on axin-induced S45 phosphorylation, in comparison to its effect on the constitutive phosphorylation of 45PKA. CKI-7 treatment diminished the axin-induced p45 signal of wild-type $\beta$-catenin, but did not affect the p45 phosphorylation of 45PKA (Fig. 5c). The inhibitor effect was further tested on S45 phosphorylation of endogenous $\beta$-catenin in proteosome-inhibited HeLa cells (Fig. 5d): CKI-7 suppressed both S45/T41 and S33 phosphorylation (Fig. 5d, lane 3), whereas the GSK-3 $\beta$ inhibitor LiCl exclusively blocked S33 phosphorylation (Fig. 5d, lane 6). In the same experiment, H89, a PKA inhibitor, had no effect on endogenous $\beta$-catenin phosphorylation (Fig. $5 d$, lane 5). Cumulatively, these in vitro and in vivo results indicate that CKI mediates the function of axin in initiating the $\beta$-catenin phosphorylation-degradation cascade.

\section{S45 phosphorylation is regulated by Wnt signaling through Dvl}

The control of $\beta$-catenin stability is a major task of the Wnt pathway and is mediated through members of the conserved protein family dishevelled (Dvl 1,2,3; Boutros and Mlodzik 1999). The current model suggests that Dvl relays the Wnt signal while associated with axin (Kishida et al. 1999; Smalley et al. 1999; Salic et al. 2000). As we have shown that axin controls the initiating event in the $\beta$-catenin phosphorylation-degradation cascade, it remained to be seen whether Wnt and Dvl regulate S45 phosphorylation. To this end, we first stimulated several cell lines with Wnt3A (Roelink and Nusse 1991; Shibamoto et al. 1998; Lee et al. 1999) and monitored S45 phosphorylation by Western blot analysis. Wnt stimulation stabilized endogenous $\beta$-catenin in mouse L-cells (fibroblasts; Fig. 6a, lanes 1,2) and exogenous $\beta$-catenin in Jurkat lymphocytes (Fig. 6a, lanes 5,6). It did not affect the levels of an already stabilized S37-mutated $\beta$-catenin

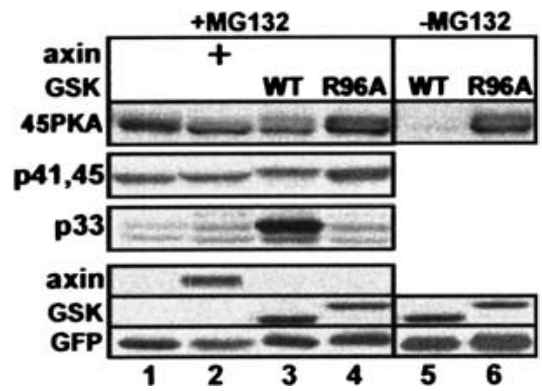

Figure 4. Axin-independent, surrogate phosphorylation at S45 promotes the GSK-3 $\beta$ phosphorylation cascade, resulting in $\beta$-catenin degradation. All cells were transfected with the $\beta$-catenin mutant 45PKA and the indicated expression vectors. HA-GSK-3 $\beta$ (WT) or Flag-R96A-GSK-3 $\beta$ (R96A) was detected using anti-GSK-3 $\beta$ antibodies (GSK-3 $\beta$ position varies according to its tag). 
a

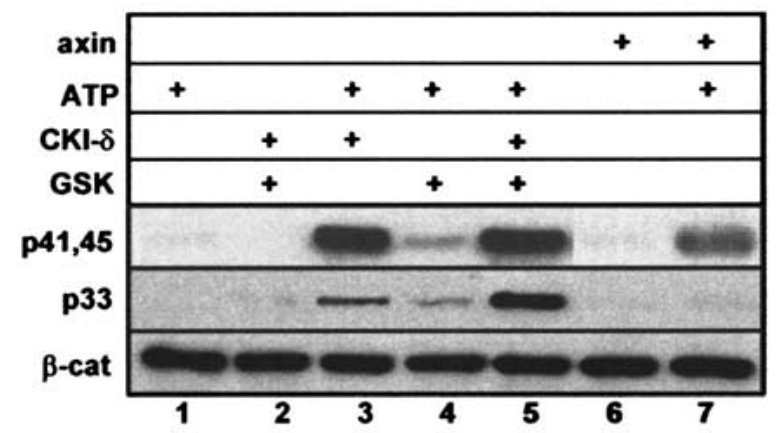

C

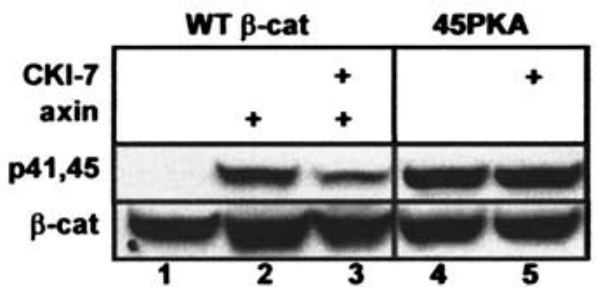

b

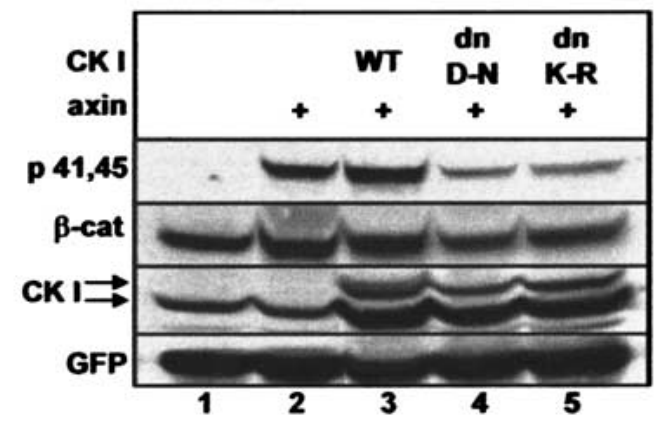

d

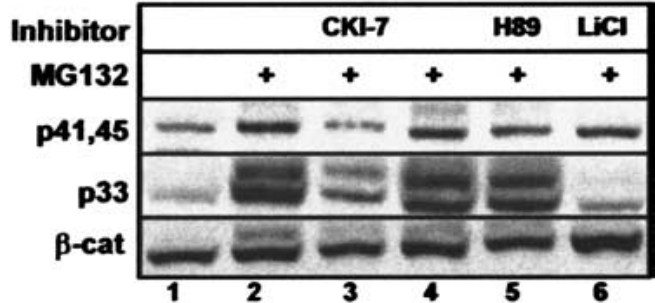

Figure 5. Identification of the $\beta$-catenin S45 kinase. (a) Immunopurified axin and recombinant CKI (aa1-318) phosphorylate $\beta$-catenin in vitro at $S 45$, creating a priming site for sequential phosphorylation at $S 33 / 37$ by recombinant GSK-3 $\beta$. Flag- $\beta$-catenin was immunoprecipitated from transfected 293 cells and subjected to an in vitro kinase assay using the indicated kinase or immunopurified Flag-axin from 293 transfectants, with or without ATP $(30 \mu \mathrm{M})$. $\beta$-Catenin phosphorylation was analyzed by Western blot, using anti-phospho- $\beta$-catenin antibodies. (b) Dominant-negative CKI inhibits axin-induced S45 phosphorylation. 293 cells were transfected with Myc- $\beta$-catenin alone (lane 1), with axin (lanes 2-5) and wild-type (lane 3), or dn-CKIE (D-N, lane 4; K-R, lane 5). The bottom CKI arrow points to the endogenous $\mathrm{hCKI} \varepsilon$, whereas the top arrow points to the exogenous xCKI $\varepsilon$ proteins detected by monoclonal anti-CKI $\varepsilon$. (c) CKI-7 inhibits the axin-induced S45 phosphorylation of wild-type $\beta$-catenin, but not the constitutive phosphorylation of 45PKA. (d) Effects of specific kinase inhibitors on the in vivo phosphorylation of $\beta$-catenin at T41, S45, and S33 in HeLa cells. CKI-7 was used at $100 \mu \mathrm{M}, \mathrm{H} 89$ at $5 \mu \mathrm{M}$, and $\mathrm{LiCl}$ at $40 \mathrm{mM}$. $\beta$-Catenin was detected with anti- $\beta$-catenin antibody or anti-phospho- $\beta$-catenin antibodies.

in the SNU449 hepatoma cell line (Fig. 6a, lanes 9-11; Satoh et al. 2000). S45 phosphorylation of $\beta$-catenin was evident in proteasome-inhibited L cells (Fig. 6a, lane 3), Jurkat cells (Fig. 6a, lane 7), and HeLa cells (Fig. 6a, lane 14). It was also apparent in okadaic acid-treated SNU449 cells (OKA, Fig. 6a, lane 10). Wnt3A treatment resulted in inhibition of $\mathrm{S} 45$ phosphorylation in all four cell lines (Fig. 6a, lanes 4,8,11,15), and the subsequent inhibition of S33/37 phosphorylation in Jurkat, HeLa, and L cells (Fig. 6a, lanes 8,15,4), suggesting that Wnt signaling intervenes between axin and S45 phosphorylation.

To examine the role of Dvl in the regulation of S45 phosphorylation, we introduced mouse Dvl-1 (Lee et al. 1999) into the 293 system and evaluated S45 phosphorylation by Western blot and MS analysis. Dvl transfection resulted in nearly complete inhibition of axin-induced S45 phosphorylation (Fig. 6b, lanes 5,6 ), in parallel to stabilizing $\beta$-catenin (Fig. 6b, lane 9). A similar effect of Dvl was observed for the L525P-axin-induced S45 phosphorylation: MS (Fig. 6c) and Western blot analysis (data not shown) indicated that Dvl inhibits the axin-CKIinduced S45 phosphorylation. However, Dvl, as a Wnt signal mediator, could also regulate the subsequent steps of the GSK- $3 \beta$ phosphorylation cascade. To evaluate this possible dual role of Dvl, we coexpressed Dvl with the
45PKA $\beta$-catenin mutant that initiates the GSK-3 $\beta$ cascade independently of axin (Fig. 4). Dvl had no effect on PKA-mediated S45 phosphorylation (Fig. 6d, cf. lanes 1 and 2), nor did it block the GSK-3 $\beta$-mediated S33/37 phosphorylation (Fig. 6d, lanes 3,4). Likewise, in striking difference to Dvl's stabilizing effect on wild-type $\beta$-catenin (Fig. 6b, lanes 8,9), 45PKA degradation was not inhibited by Dvl (Fig. 6d, lanes 6,7). This finding indicates that the axin/CKI-mediated S45 phosphorylation event, is a critical target for Wnt signaling.

\section{Discussion}

Our studies were aimed to address certain key questions in the regulation of the Wnt- $\beta$-catenin pathway, namely, what molecular events trigger the phosphorylation-degradation cascade of $\beta$-catenin and which of them is a target for Wnt regulation. We conclude that a major role of axin in the Wnt pathway is to provide the kinase activity that initiates the $\beta$-catenin phosphorylation cascade at S45 (Fig. 7a). This process is mediated by CKI, the $\alpha, \delta$, or $\varepsilon$ isoform, all detected in association with axin by LC/MS. Yet, under specific physiological settings, a particular CKI isoform may function with axin. Association of axin with a single CKI isoform may require an inter- 
Amit et al.
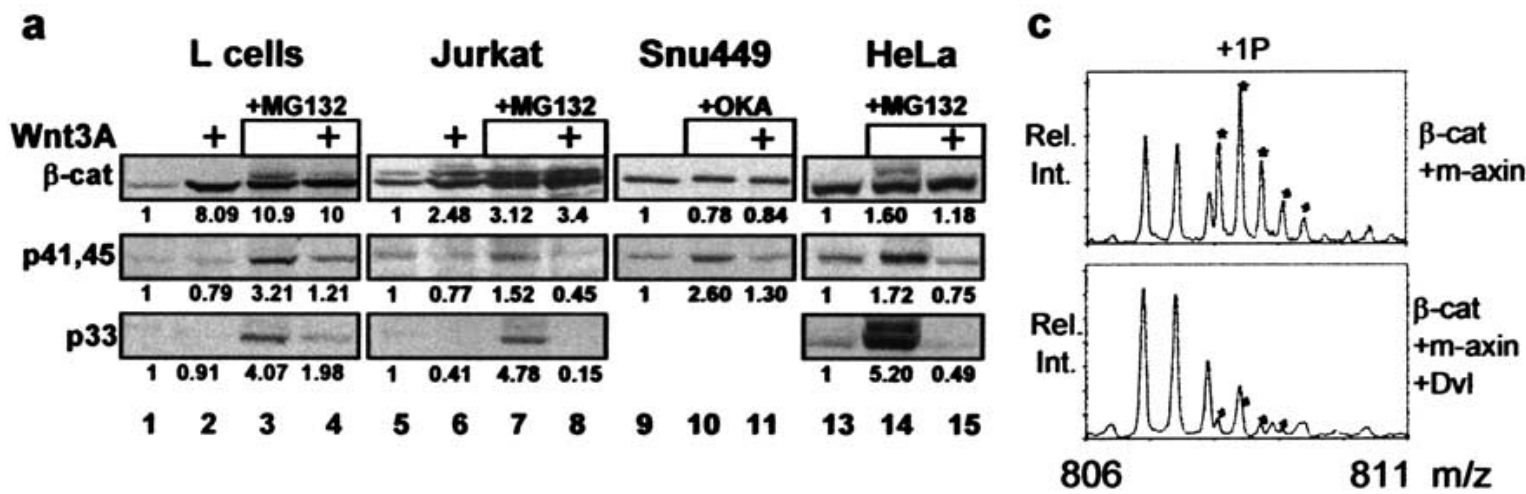

b
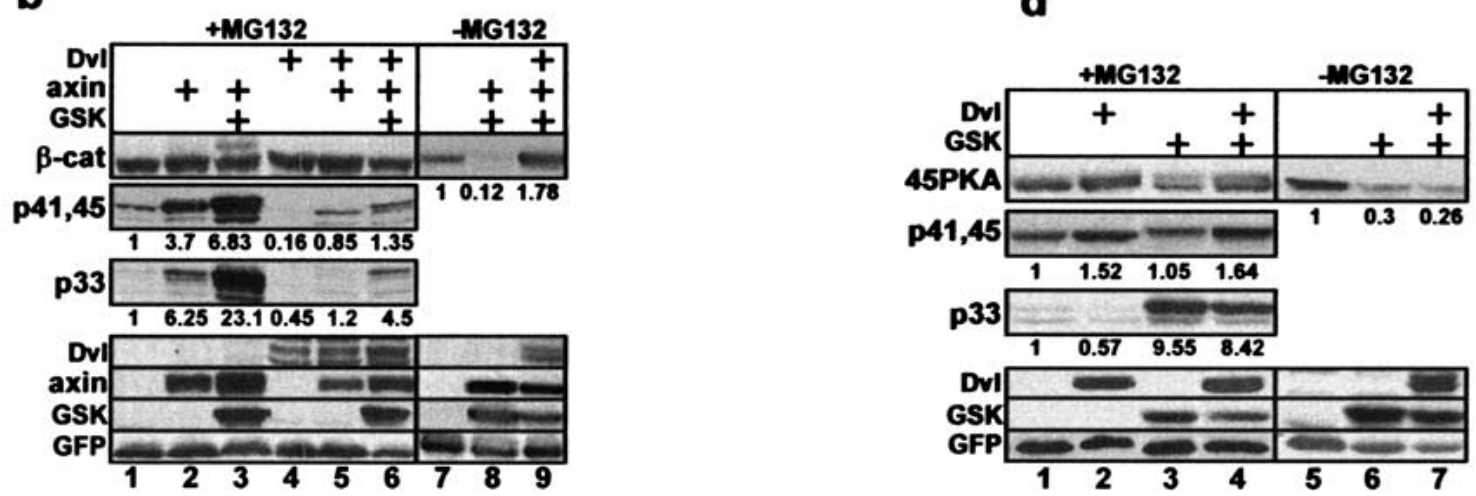

Figure 6. The Wnt pathway targets the axin-mediated priming phosphorylation of $\beta$-catenin at S45. (a) Wnt3A inhibits S45 phosphorylation. Mouse L cells, $\beta$-catenin transfected Jurkat T cells, SNU449 hepatoma cells (Satoh et al. 2000), and HeLa cells were incubated (5 h) with conditioned medium of wild-type or Wnt3A-secreting L cells (Shibamoto et al. 1998). MG-132 or okadaic acid (OKA, $1 \mu \mathrm{M}$ ) was added to the indicated cultures. Endogenous (HeLa, L cells, and SNU449) and exogenous (Jurkat) $\beta$-catenin was detected with anti- $\beta$-catenin antibody, or anti-phospho- $\beta$-catenin antibodies. The numbers under the different lanes are relative densitometry figures, referring to the signal intensity of untreated cultures. (b) Dvl-1 inhibits axin-mediated S45 phosphorylation. Mass spectra of the Asp32-Glu55 peptide with one phosphate group (+1P): from $\beta$-catenin coexpressed with L525P-axin (m-axin), compared with that of $\beta$-catenin coexpressed with L525P-axin and Dvl-1. (c) Dvl-1 overexpression results in inhibition of S45 phosphorylation and $\beta$-catenin stabilization. $\beta$-Catenin of 293 transfectants was detected using anti-Myc or anti-phospho- $\beta$-catenin antibodies. $(d)$ Dvl-1 has no effect on axin-independent, S45-phosphorylation-initiated GSK-3 $\beta$ cascade: Analysis of 45PKA-transfected cells.

mediate molecule, such as the adapter protein diversin (T. Schwarz-Romond, C. Asbrand, J. Bakkers, M. Kuhl, H.-J. Schaffer, J. Huelsken, J. Behrens, M. Hammerschmidt, and W. Birchmeier, in prep.). S45 phosphorylation by the axin-CKI complex is necessary and sufficient to mobilize a GSK3-mediated cascade (Fig. 7b,c). This indicates, that contrary to prevailing models (Ali et al. 2001; Cohen and Frame 2001; Dajani et al. 2001; Frame et al. 2001; Harwood, 2001), association with axin does not substitute for the $+4 \mathrm{p}$ priming of GSK3. The ensuing GSK3 cascade culminates in $\beta$-catenin phosphorylation at $\mathrm{S} 33 / 37$, creating a docking site for the $\mathrm{SCF}^{\beta-\operatorname{TrCP}}$ ubiquitin ligase (Fig. 7d). Our experiments did not reveal a specific mechanism that regulates the GSK3-phosphorylation cascade once it has been initiated. Nevertheless, it is conceivable that whenever GSK3 is limiting, it will fail to phosphorylate $\beta$-catenin, unless supported by axin (see, e.g., Fig. 3c). Then, any signal (including a Wnt signal) that would affect the affinity of association between axin and GSK3 might influence the progression of the $\beta$-catenin phosphorylation cascade. On the other hand, under nonlimiting GSK3 levels (e.g., in the brain; Woodgett 1990), or GSK3 overexpression (Fig. 6d), Wnt signaling through Dvl is not likely to affect GSK3-dependent progression of the phosphorylation cascade. This is in contrast to Dvl suppression of S45 phosphorylation, which cannot be overridden by the overexpression of axin (Fig. 6b,c). It appears, therefore, that the phosphorylation of $\beta$-catenin at S45 is a major regulated molecular event of the Wnt signaling pathway (Fig. 7e). While this manuscript was being reviewed, Liu and colleagues published similar results pointing to a dual-kinase mechanism for $\beta$-catenin phosphorylation-degradation (Liu et al. 2002). However, there is one major difference between the two manuscripts: whereas we show that Wnt3A signaling and Dvl overexpression regulate S45 phosphorylation, Liu et al. maintain that Wnt signaling regulates $\beta$-catenin stabilization through GSK3. The reason for the discrepancy is probably attributable to the experimental procedure used in studying the regula- 

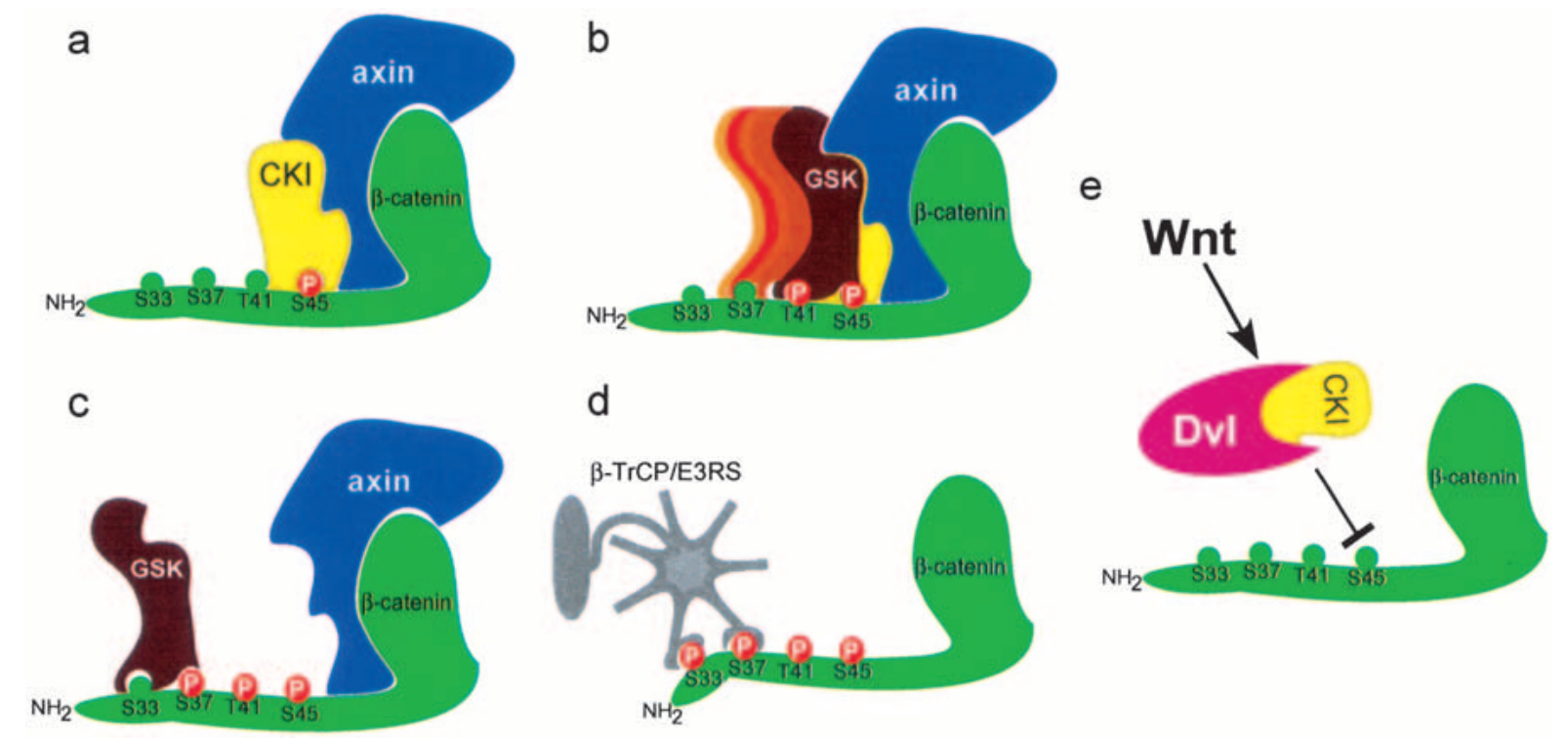

Figure 7. A model depicting the $\beta$-catenin phosphorylation-degradation cascade. (a) Axin recruits CKI to phosphorylate $\beta$-catenin at S45. $(b, c)$ S45 phosphorylation primes $\beta$-catenin for the succeeding GSK-3 $\beta$ phosphorylation cascade, finally hitting the S33/37 sites. (d) Phosphorylation at S33/37 creates a docking site for $\beta$-TrCP/E3RS, promoting the ubiquitination and degradation of $\beta$-catenin. (e) Wnt signaling, possibly through Dvl and CKI, regulates S45 phosphorylation.

tion of S45 phosphorylation of endogenous $\beta$-catenin. To observe the full extent of S45 phosphorylation, $\beta$-catenin has to be stabilized. This may be achieved by proteasomal inhibition, or by using a cell line mutated at phosphorylation sites upstream of S45 (see Fig. 6a). Under these conditions, all four tested cell lines (including a colon carcinoma-derived cell line harboring a Ser $37 \mathrm{mu}$ tated $\beta$-catenin) responded to Wnt3A by down-regulating the entire phosphorylation cascade from S45 onward (Fig. 6a). The mechanism by which Wnt signaling suppresses S45 phosphorylation is as yet unknown. In essence, induction of S45 dephosphorylation or inactivation of the S45 kinase complex may be involved. The latter may be achieved by preventing the interaction of the axin-CKI complex with $\beta$-catenin, generating molecular rearrangements within the multiprotein kinase complex, or inducing posttranslational modification of a complex component.

Identification of CKI as an essential component of the S45 kinase complex assigns this enzyme a role as an Wnt antagonist. This is in agreement with the proposal that CKI supports the $\beta$-catenin degradation complex through APC phosphorylation (Rubinfeld et al. 2001) and apparently contradictory to certain developmental studies in Xenopus and Caenorhabditis elegans implicating CKI as a Wnt effector (Peters et al. 1999). However, more recent studies support an antagonistic relationship between Wnt and CKI: (1) Diversin, which links axin/conductin to CKI, induces the degradation of $\beta$-catenin and thwarts a Wnt signal in Xenopus and zebrafish development ( $\mathrm{T}$. Schwarz-Romond, C. Asbrand, J. Bakkers, M. Kuhl, H.-J. Schaffer, J. Huelsken, J. Behrens, M. Hammerschmidt, and W. Birchmeier, in prep.). (2) CKI depletion by RNA interference in Drosophila embryos results in the naked cuticle phenotype, a developmental hallmark of Wingless/Wnt signaling (Liu et al. 2002; Yanagawa et al. 2002). How can these conflicting data on the role of CKI in Wnt signaling be reconciled with our results? It is conceivable that certain developmental assays (e.g., induction of axis duplication in Xenopus) obscure the important physiological role of CKI in triggering $\beta$-catenin degradation. This could be explained by the dual role of CKI in the Wnt pathway; its positive role upon Wnt signaling (i.e., $\beta$-catenin stabilization) predominating over its negative role in initiating $\beta$-catenin degradation. In the absence of a Wnt signal, CKI associates and cooperates with axin in launching the $\beta$-catenin phosphorylation-degradation cascade (Rubinfeld et al. 2001; our MS data). On the other hand, upon confronting a Wnt signal, CKI interacts and synergizes with Dvl in stabilizing $\beta$-catenin (Peters et al. 1999; Kishida et al. 2001; McKay et al. 2001; Gao et al. 2002). In principle, the putative dual function of CKI could be mediated by different enzyme isoforms. Yet, regardless of the particular isoform involved, the role of CKI in Wnt activation of Dvl appears to exceed its effect on S45 phosphorylation. Future studies may uncover the mechanism of the proposed dual function of CKI in the Wnt pathway.

\section{Materials and methods}

\section{$\beta$-Catenin expression system}

293 cells were transiently transfected using the calcium phosphate procedure. The following expression vectors were used: Myc- or Flag-tagged $\beta$-catenin $(0.5 \mu$; a human $\beta$-catenin clone obtained from R. Grosschedl, University of Munich, Germany), Flag- or Myc-tagged axin ( $2 \mu \mathrm{g}$; mouse cDNA provided by $\mathrm{F}$. Costantini, Columbia University, New York, NY), and HA- 
GSK3 $\beta$ or Flag-GSK3 $\beta$ (3.5 $\mu$; a rabbit clone obtained from J.R. Woodgett; Woodgett 1990). $\beta$-Catenin mutants include DP (S33, S37, T40, S45, S47 substituted to alanine), single-point mutants (S29F, S33Y, S37A, T41A, S45F), and 45PKA (T41S, T42R, A43R). Additional vectors were Flag-WD, a dominant-negative $\beta$-TrCP fragment ( $\Delta$ F-box; Yaron et al. 1998); Flag-Dvl-1 (a mouse cDNA clone obtained from S.-I. Yanagawa; Lee et al. 1999), and wild-type and dominant-negative Xenopus CKI $\varepsilon$ (XCKI $\varepsilon$-D128N and K85R; provided by T. Schwarz-Romond; McKay et al. 2001). Cells were harvested and processed for the various experiments $24-48 \mathrm{~h}$ after transfection. MG-132 (Sigma) was used at $20 \mu \mathrm{M}$ for $5 \mathrm{~h}$; $\mathrm{LiCl}(40 \mathrm{mM})$ was added for $6 \mathrm{~h}$, and CKI-7 $(100 \mu \mathrm{M})$ for $16 \mathrm{~h}$ prior to harvesting. $\beta$-Catenin, axin, and GSK-3 $\beta$ in cell lysates were detected using anti-Myc (Ab-1, Oncogenes Research Products, $2 \mu \mathrm{g} / \mathrm{mL}$ ), anti-Flag (M2, Sigma, 1 $\mu \mathrm{g} / \mathrm{mL}$ ), and anti-HA (12CA5 ascites fluid; 1:5000) antibodies, respectively. GFP expression was monitored with anti-GFP antibody (JL-8, Clontech, $1 \mu \mathrm{g} / \mathrm{mL}$ ). In some experiments (Fig. 4), GSK-3 $\beta$ was detected using anti-GSK- $3 \beta$ monoclonal antibodies (clone 7, Transduction Laboratories, $0.1 \mu \mathrm{g} / \mathrm{mL}$ ). Endogenous and exogenous $\beta$-catenin (Figs. $5 \mathrm{~d}$ and $6 \mathrm{a}$ ) were detected with anti- $\beta$-catenin antibodies (clone 14, Transduction Laboratories, $0.25 \mu \mathrm{g} / \mathrm{mL}$ ).

\section{In vitro kinase assay}

For in vitro kinase assay, $250 \mu \mathrm{g}$ of protein lysate from Flag- $\beta$ catenin 293 transfectants was immunoadsorbed by M2 Flagaffinity beads, and used as a substrate for kinase reactions. Immunobeads were incubated in kinase buffer containing $50 \mathrm{mM}$ Tris (pH 7.5), $10 \mathrm{mM} \mathrm{MgCl}, 5 \mathrm{mM}$ DTT, $5 \%$ glycerol, ATP (30 $\mu \mathrm{M}$ ), and phosphatase inhibitors. Recombinant CKI- $\delta$ (aa1-318 fragment; 200 U; New England Biolabs), GSK-3 $\beta$ (20 U, New England Biolabs), or immunopurified Flag-axin $(0.2 \mu \mathrm{g}$ of protein, peptide-eluted from an immunobead-adsorbed 293 lysate) was added to the reaction mix at $30{ }^{\circ} \mathrm{C}$ for $30 \mathrm{~min}$. Sequential $\beta$-catenin phosphorylation was performed by adding GSK-3 $\beta 15$ min after CKI- $\delta$ and further incubation for $15 \mathrm{~min}$

\section{$\beta$-Catenin phosphorylation analysis}

For Western blot analysis, three different commercial anti- $\beta$ catenin phosphopeptide antibodies were used: (1) anti-phosphoThr 41/Ser 45 (Cell Signaling Technology), a polyclonal antibody specific for both pT41 and pS45 $(\alpha \mathrm{p} 41,45)$; (2) anti-phospho-Ser 33/37/Thr 41 (Cell Signaling Technology), a polyclonal antibody recognizing pS33 ( $\alpha \mathrm{p} 33$ ) (these two polyclonal antibodies were used at a 1:1000 dilution, according to the manufacturer's instructions); (3) anti-phospho-Ser 33/37 (BC-22, Sigma), a monoclonal antibody specific for pS37 (used as ascites fluid at a 1:3000 dilution; $\alpha \mathrm{p} 37$ ). Antibody specificities were determined by phosphopeptide inhibition studies. $\mathrm{D}^{32} \mathrm{~S}\left(\mathrm{PO}_{4}\right)$ GIHSGATTTAPS ${ }^{45}$ abolished the $\alpha$ p 33 , but not the $\alpha$ p 37 signal; $\mathrm{D}^{32}$ SGIHS $\left(\mathrm{PO}_{4}\right)$ GATTTAPS ${ }^{45}$ blocked the $\alpha$ p37 but not the $\alpha$ p33 signal. The $\beta$-catenin phosphorylation signal of $\alpha$ p41,45 was inhibited by two $\beta$-catenin phosphopeptides: partially by $\mathrm{G}^{34} \mathrm{IHS}\left(\mathrm{PO}_{4}\right) \mathrm{GATT}\left(\mathrm{PO}_{4}\right) \mathrm{TA}^{43}$ and completely by $\mathrm{G}^{38} \mathrm{ATT}\left(\mathrm{PO}_{4}\right)-$ TAPS $\left(\mathrm{PO}_{4}\right) \mathrm{LS}^{47}$, indicating that both pT41 and pS45 are recognized by the antibodies. For MS analysis, proteins were immunopurified by M2 Flag-affinity beads (Sigma), separated by SDS-PAGE, and Coomassie-stained; the $\beta$-catenin bands were in-gel digested with endoproteinase Asp-N. The resulting peptides were desalted on small columns, eluted with $20 \% \mathrm{MeOH}$, $5 \% \mathrm{HCOOH}$, and analyzed by nanoelectrospray mass spectrometry (see Yaron et al. 1998), using a quadrupole time-of-flight (TOF) mass spectrometer (PE-Sciex).

\section{LC MS/MS analysis of axin-associated kinases}

Flag-axin-associated proteins were dissolved in $8 \mathrm{M}$ urea, 100 $\mathrm{mM}$ Tris-HCI ( $\mathrm{pH} 8.0)$, treated with DTT and iodoacetamide, digested with endoproteinase Lys-C, and further digested with trypsin after dilution. Resulting peptides were loaded onto a

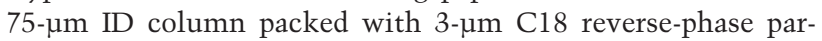
ticles (Vydac) and eluted into a quadrupole-TOF mass spectrometer (PE-Sciex) with an acetonitrile gradient. Fragment ion spectra were recorded using information-dependent acquisition and duty-cycle enhancement. Proteins were identified in the NCBI database using the Mascot program (Matrix Science).

\section{Acknowledgments}

We thank W. Birchmeier, F. Costantini, R. Grosschedl, R. Nusse, B. Vogelstein, J.R. Woodgett, S.-I. Yanagawa, and SigmaIsrael for providing invaluable reagents, A. Bar-Sinai for his contribution to the initial studies, and A. Yaron for comments on the manuscript. This research was supported by grants from the Israel Science Foundation funded by the Israel Academy for Sciences and Humanities-Centers of Excellence Program, the German-Israeli Program (DIP), and Boehringer Ingelheim International. Work at the Protein Interaction Laboratory was supported by a grant from the Danish National Research Foundation to the Centre for Experimental Bioinformatics.

The publication costs of this article were defrayed in part by payment of page charges. This article must therefore be hereby marked "advertisement" in accordance with 18 USC section 1734 solely to indicate this fact.

\section{References}

Aberle, H., Bauer, A., Stappert, J., Kispert, A., and Kemler, R. 1997. $\beta$-Catenin is a target for the ubiquitin-proteasome pathway. EMBO J. 16: 3797-3804.

Ali, A., Hoeflich, K.P., and Woodgett, J.R. 2001. Glycogen synthase kinase-3: Properties, functions, and regulation. Chem. Rev. 101: 2527-2540.

Bax, B., Carter, P.S., Lewis, C., Guy, A.R., Bridges, A., Tanner, R., Pettman, G., Mannix, C., Culbert, A.A., Brown, M.J., et al. 2001. The structure of phosphorylated GSK-3 $\beta$ complexed with a peptide, FRATtide, that inhibits $\beta$-catenin phosphorylation. Structure (Camb) 9: 1143-1152.

Behrens, J., Jerchow, B.A., Wurtele, M., Grimm, J., Asbrand, C., Wirtz, R., Kuhl, M., Wedlich, D., and Birchmeier, W. 1998. Functional interaction of an axin homolog, conductin, with $\beta$-catenin, APC, and GSK3 $\beta$. Science 280: 596-599.

Bienz, M. and Clevers, H. 2000. Linking colorectal cancer to Wnt signaling. Cell 103: 311-320.

Boutros, M. and Mlodzik, M. 1999. Dishevelled: At the crossroads of divergent intracellular signaling pathways. Mech. Dev. 83: 27-37.

Chijiwa, T., Hagiwara, M., and Hidaka, H. 1989. A newly synthesized selective casein kinase I inhibitor, $\mathrm{N}$-(2-aminoethyl)-5-chloroisoquinoline-8-sulfonamide, and affinity purification of casein kinase I from bovine testis. J. Biol. Chem. 264: 4924-4927.

Cohen, P. and Frame, S. 2001. TIMELINE: The renaissance of GSK3. Nat. Rev. Mol. Cell. Biol. 2: 769-776.

Dajani, R., Fraser, E., Roe, S.M., Young, N., Good, V., Dale, T.C., and Pearl, L.H. 2001. Crystal structure of glycogen synthase kinase $3 \beta$ : Structural basis for phosphate-primed substrate specificity and autoinhibition. Cell 105: 721-732. 
Ding, V.W., Chen, R.H., and McCormick, F. 2000. Differential regulation of glycogen synthase kinase $3 \beta$ by insulin and Wnt signaling. J. Biol. Chem. 275: 32475-32481.

Eastman, Q. and Grosschedl, R. 1999. Regulation of LEF-1/TCF transcription factors by Wnt and other signals. Curr. Opin. Cell Biol. 11: 233-240.

Farr III, G.H., Ferkey, D.M., Yost, C., Pierce, S.B., Weaver, C., and Kimelman, D. 2000. Interaction among GSK-3, GBP, axin, and APC in Xenopus axis specification. J. Cell Biol. 148: 691-702.

Fearnhead, N.S., Britton, M.P., and Bodmer, W.F. 2001. The ABC of APC. Hum. Mol. Genet. 10: 721-733.

Fish, K.J., Cegielska, A., Getman, M.E., Landes, G.M., and Virshup, D.M. 1995. Isolation and characterization of human casein kinase I epsilon (CKI), a novel member of the CKI gene family. J. Biol. Chem. 270: 14875-14883.

Frame, S., Cohen, P., and Biondi, R.M. 2001. A common phosphate binding site explains the unique substrate specificity of GSK3 and its inactivation by phosphorylation. Mol. Cell 7: 1321-1327.

Fraser, E., Young, N., Dajani, R., Franca-Koh, J., Ryves, J., Williams, R.S., Yeo, M., Webster, M.T., Richardson, C., Smalley, M.J., et al. 2002. Identification of the axin and FRAT binding region of glycogen synthase kinase-3. J. Biol. Chem. 277: 2176-2185.

Gao, Z.H., Seeling, J.M., Hill, V., Yochum, A., and Virshup, D.M. 2002. Casein kinase I phosphorylates and destabilizes the $\beta$-catenin degradation complex. Proc. Nat1. Acad. Sci. 99: $1182-1187$.

Groden, J., Thliveris, A., Samowitz, W., Carlson, M., Gelbert, L., Albertsen, H., Joslyn, G., Stevens, J., Spirio, L., Robertson, M., et al. 1991. Identification and characterization of the familial adenomatous polyposis coli gene. Cell 66: 589-600.

Hart, M.J., de los Santos, R., Albert, I.N., Rubinfeld, B., and Polakis, P. 1998. Downregulation of $\beta$-catenin by human axin and its association with the APC tumor suppressor, $\beta$-catenin and GSK3 $\beta$. Curr. Biol. 8: 573-581.

Hart, M., Concordet, J.P., Lassot, I., Albert, I., del los Santos, R., Durand, H., Perret, C., Rubinfeld, B., Margottin, F., Benarous, R., et al. 1999. The F-box protein $\beta-\operatorname{TrCP}$ associates with phosphorylated $\beta$-catenin and regulates its activity in the cell. Curr. Biol. 9: 207-210.

Harwood, A.J. 2001. Regulation of GSK-3: A cellular multiprocessor. Cell 105: 821-824.

Hinoi, T., Yamamoto, H., Kishida, M., Takada, S., Kishida, S., and Kikuchi, A. 2000. Complex formation of adenomatous polyposis coli gene product and axin facilitates glycogen synthase kinase-3 $\beta$-dependent phosphorylation of $\beta$-catenin and down-regulates $\beta$-catenin. J. Biol. Chem. 275: 3439934406.

Huelsken, J. and Birchmeier, W. 2001. New aspects of Wnt signaling pathways in higher vertebrates. Curr. Opin. Genet. Dev. 11: 547-553.

Ikeda, S., Kishida, S., Yamamoto, H., Murai, H., Koyama, S., and Kikuchi, A. 1998. Axin, a negative regulator of the Wnt signaling pathway, forms a complex with GSK-3 $\beta$ and $\beta$-catenin and promotes GSK-3 $\beta$-dependent phosphorylation of $\beta$-catenin. EMBO J. 17: 1371-1384.

Kinzler, K.W., Nilbert, M.C., Su, L.K., Vogelstein, B., Bryan, T.M., Levy, D.B., Smith, K.J., Preisinger, A.C., Hedge, P., McKechnie, D., et al. 1991. Identification of FAP locus genes from chromosome 5q21. Science 253: 661-665.

Kishida, M., Hino, S., Michiue, T., Yamamoto, H., Kishida, S. Fukui, A., Asashima, M., and Kikuchi, A. 2001. Synergistic activation of the Wnt signaling pathway by Dvl and casein kinase Iє. J. Biol. Chem. 276: 33147-33155.
Kishida, S., Yamamoto, H., Hino, S., Ikeda, S., Kishida, M., and Kikuchi, A. 1999. DIX domains of Dvl and axin are necessary for protein interactions and their ability to regulate $\beta$-catenin stability. Mol. Cell. Biol. 19: 4414-4422.

Kitagawa, M., Hatakeyama, S., Shirane, M., Matsumoto, M. Ishida, N., Hattori, K., Nakamichi, I., Kikuchi, A., and Nakayama, K. 1999. An F-box protein, FWD1, mediates ubiquitin-dependent proteolysis of $\beta$-catenin. EMBO J. 18: 24012410.

Klein, P.S. and Melton, D.A. 1996. A molecular mechanism for the effect of lithium on development. Proc. Natl. Acad. Sci. 93: 8455-8459.

Latres, E., Chiaur, D.S., and Pagano, M. 1999. The human F box protein $\beta$-Trcp associates with the Cull/Skp1 complex and regulates the stability of $\beta$-catenin. Oncogene 18: 849-854.

Lee, E., Salic, A., and Kirschner, M.W. 2001. Physiological regulation of $\beta$-catenin stability by Tcf3 and CK1є. J. Cell Biol. 154: 983-993.

Lee, J.S., Ishimoto, A., and Yanagawa, S. 1999. Characterization of mouse dishevelled (Dvl) proteins in Wnt/Wingless signaling pathway. J. Biol. Chem. 274: 21464-21470.

Li, L., Yuan, H., Weaver, C.D., Mao, J., Farr III, J.H., Sussman, D.J., Jonkers, J., Kimelman, D., and Wu, D. 1999. Axin and Fratl interact with dvl and GSK, bridging Dvl to GSK in Wnt-mediated regulation of LEF-1. EMBO J. 18: 4233-4240.

Liu, C., Li, Y., Semenov, M., Han, C., Baeg, G.-H., Tan, Y., Zhang, Z., Lin, X., and He, X. 2002. Control of $\beta$-catenin phosphorylation/degradation by a dual-kinase mechanism. Cell 108: 837-847.

McKay, R.M., Peters, J.M., and Graff, J.M. 2001. The casein kinase I family: Roles in morphogenesis. Dev. Biol. 235: 378-387.

Morin, P.J., Sparks, A.B., Korinek, V., Barker, N., Clevers, H., Vogelstein, B., and Kinzler, K.W. 1997. Activation of $\beta$-catenin-Tcf signaling in colon cancer by mutations in $\beta$-catenin or APC. Science 275: 1787-1790.

Peifer, M. and Polakis, P. 2000. Wnt signaling in oncogenesis and embryogenesis: A look outside the nucleus. Science 287: 1606-1609

Peters, J.M., McKay, R.M., McKay, J.P., and Graff, J.M. 1999. Casein kinase I transduces Wnt signals. Nature 401: 345-350.

Polakis, P. 2000. Wnt signaling and cancer. Genes \& Dev. 14: $1837-1851$.

Roelink, H. and Nusse, R. 1991. Expression of two members of the Wnt family during mouse development: Restricted temporal and spatial patterns in the developing neural tube. Genes \& Dev. 5: 381-388.

Rubinfeld, B., Robbins, P., El-Gamil, M., Albert, I., Porfiri, E., and Polakis, P. 1997. Stabilization of $\beta$-catenin by genetic defects in melanoma cell lines. Science 275: 1790-1792.

Rubinfeld, B., Tice, D.A., and Polakis, P. 2001. Axin-dependent phosphorylation of the adenomatous polyposis coli protein mediated by casein kinase $1 \epsilon$. I. Biol. Chem. 276: 3903739045.

Sakanaka, C., Weiss, J.B., and Williams, L.T. 1998. Bridging of $\beta$-catenin and glycogen synthase kinase- $3 \beta$ by axin and inhibition of $\beta$-catenin-mediated transcription. Proc. Natl. Acad. Sci. 95: 3020-3023.

Sakanaka, C., Leong, P., Xu, L., Harrison, S.D., and Williams, L.T. 1999. Casein kinase $i \epsilon$ in the wnt pathway: Regulation of $\beta$-catenin function. Proc. Natl. Acad. Sci. 96: 1254812552.

Salic, A., Lee, E., Mayer, L., and Kirschner, M.W. 2000. Control of $\beta$-catenin stability: Reconstitution of the cytoplasmic steps of the wnt pathway in Xenopus egg extracts. Mol. Cell 5: 523-532. 
Amit et al.

Satoh, S., Daigo, Y., Furukawa, Y., Kato, T., Miwa, N., Nishiwaki, T., Kawasoe, T., Ishiguro, H., Fujita, M., Tokino, T., et al. 2000. AXIN1 mutations in hepatocellular carcinomas, and growth suppression in cancer cells by virus-mediated transfer of AXIN1. Nat. Genet. 24: 245-250.

Shibamoto, S., Higano, K., Takada, R., Ito, F., Takeichi, M., and Takada, S. 1998. Cytoskeletal reorganization by soluble Wnt-3a protein signalling. Genes Cells 3: 659-670.

Smalley, M.J., Sara, E., Paterson, H., Naylor, S., Cook, D., Jayatilake, H., Fryer, L.G., Hutchinson, L., Fry, M.J., and Dale, T.C. 1999. Interaction of axin and Dvl-2 proteins regulates Dvl-2-stimulated TCF-dependent transcription. EMBO $J$. 18: 2823-2835.

Sparks, A.B., Morin, P.J., Vogelstein, B., and Kinzler, K.W. 1998. Mutational analysis of the APC/ $\beta$-catenin/Tcf pathway in colorectal cancer. Cancer Res. 58: 1130-1134.

Stambolic, V., Ruel, L., and Woodgett, J.R. 1996. Lithium inhibits glycogen synthase kinase- 3 activity and mimics wingless signalling in intact cells. Curr. Biol. 6: 1664-1668.

Willert, K. and Nusse, R. 1998. $\beta$-Catenin: A key mediator of Wnt signaling. Curr. Opin. Genet. Dev. 8: 95-102.

Winston, J.T., Strack, P., Beer-Romero, P., Chu, C.Y., Elledge, S.J., and Harper, J.W. 1999. The SCF $\beta$-TRCP-ubiquitin ligase complex associates specifically with phosphorylated destruction motifs in IкB $\alpha$ and $\beta$-catenin and stimulates IкB $\alpha$ ubiquitination in vitro. Genes \& Dev. 13: 270-283.

Wodarz, A. and Nusse, R. 1998. Mechanisms of Wnt signaling in development. Annu. Rev. Cell Dev. Biol. 14: 59-88.

Wong, C.M., Fan, S.T., and Ng, I.O. 2001. $\beta$-Catenin mutation and overexpression in hepatocellular carcinoma: Clinicopathologic and prognostic significance. Cancer 92: 136-145.

Woodgett, J.R. 1990. Molecular cloning and expression of glycogen synthase kinase-3/factor A. EMBO J. 9: 2431-2438.

Yamamoto, H., Kishida, S., Uochi, T., Ikeda, S., Koyama, S., Asashima, M., and Kikuchi, A. 1998. Axil, a member of the Axin family, interacts with both glycogen synthase kinase $3 \beta$ and $\beta$-catenin and inhibits axis formation of Xenopus embryos. Mol. Cell. Biol. 18: 2867-2875.

Yamamoto, H., Kishida, S., Kishida, M., Ikeda, S., Takada, S., and Kikuchi, A. 1999. Phosphorylation of axin, a Wnt signal negative regulator, by glycogen synthase kinase- $3 \beta$ regulates its stability. J. Biol. Chem. 274: 10681-10684.

Yanagawa, S., Matsuda, Y., Lee, J., Matsubayashi, H., Sese, S., Kadowaki, T., and Ishimoto, A. 2002. Casein Kinase I phosphorylates the armadillo protein and induces its degradation in Drosophila. EMBO J. (in press).

Yaron, A., Hatzubai, A., Davis, M., Lavon, I., Amit, S., Manning, A.M., Andersen, J.S., Mann, M., Mercurio, F., and Ben-Neriah, Y. 1998. Identification of the receptor component of the ІкВ $\alpha$-ubiquitin ligase. Nature 396: 590-594.

Zeng, L., Fagotto, F., Zhang, T., Hsu, W., Vasicek, T.J., Perry III, W.L., Lee, J.J., Tilghman, S.M., Gumbiner, B.M., and Costantini, F. 1997. The mouse Fused locus encodes axin, an inhibitor of the Wnt signaling pathway that regulates embryonic axis formation. Cell 90: 181-192. 


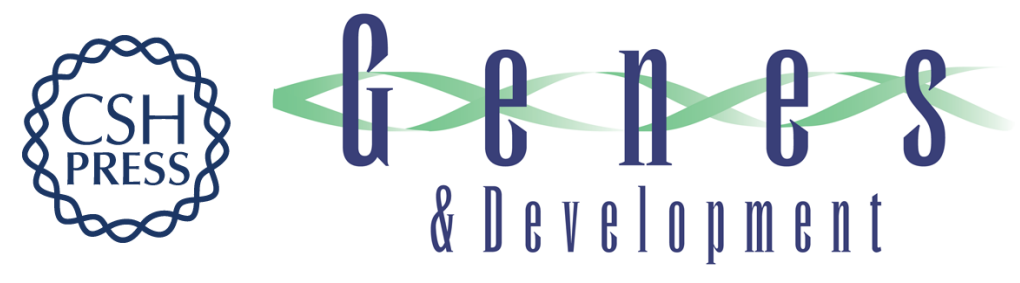

\section{Axin-mediated CKI phosphorylation of $\beta$-catenin at Ser 45: a molecular switch for the Wnt pathway}

Sharon Amit, Ada Hatzubai, Yaara Birman, et al.

Genes Dev. 2002, 16:

Access the most recent version at doi:10.1101/gad.230302

$\begin{array}{ll}\text { References } & \begin{array}{l}\text { This article cites } 59 \text { articles, } 31 \text { of which can be accessed free at: } \\ \text { http://genesdev.cshlp.org/content/16/9/1066.full.html\#ref-list-1 }\end{array}\end{array}$

License

Email Alerting Receive free email alerts when new articles cite this article - sign up in the box at the top Service right corner of the article or click here.

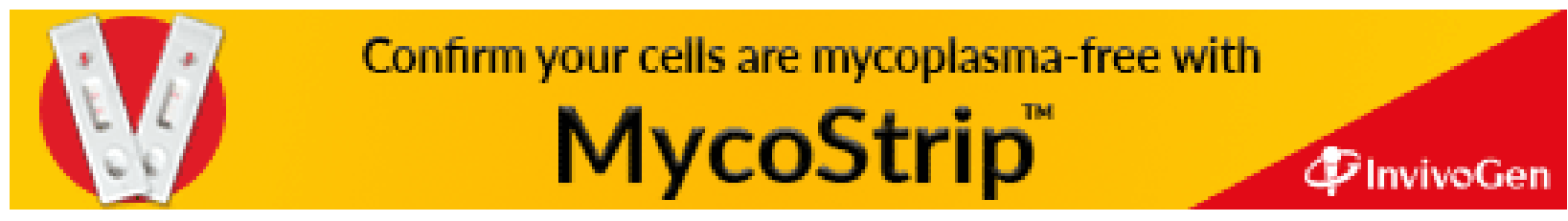

